\title{
La gloria de los Vencidos. Diego San José
}

\author{
José Antonio Cortés Manzanedo \\ Universidad de Murcia
}

La editorial Renacimiento, promotora de la «Biblioteca del Rescate», es una vez más la liberadora de escritores atrapados en un pasado turbulento e incierto. Este es el caso de Por Dios y por España, de Diego San José, una novela «episódica» e inédita que, escrita en la clandestinidad, por las posibles consecuencias, es ahora puesta en conocimiento del lector. En colaboración con Aníbal Salazar Anglada, doctor en Literatura Hispanoamericana por la Universidad de Sevilla y editor de numerosas obras en esta colección, entre las que se encuentran las de San José, la editorial ofrece, gracias al indudable testimonio de este escritor, los oscuros momentos del asedio de Madrid por la horda franquista. Mucho más que un testimonio almibarado, como los muchos que vanaglorian la figura del dictador, es una bajada a un infierno de bombas, muerte y destrucción en el Madrid republicano.

Enlazando con las tres anteriores publicaciones, Memorias de un gato $^{1}$, De cárcel en cárcel $^{2}$ y Nos vemos en Chicote 3 , a esta última de Juan Antonio Ríos Carratalá, la actual entronca centralmente con la problemática bélica de aquellos hechos «civiles». A partir de esta contextualización, San José nos presenta una «intrahistoria» que circunda a dos protagonistas y una ciudad que empieza a desvanecerse entre escombros y sangre. Pero, antes de eso, Salazar Anglada nos involucra como lectores en la antesala a la lectura: una profunda investigación que pone de relieve determinados aspectos nunca antes esclarecidos del escritor y su vida. Uno de los detalles que sobresalen dentro de la propia investigación es el descubrimiento de un segundo título de la obra, Al paso alegre de la paz, además de la historia que precede a cada una de las palabras que componen esta lúgubre y aneblada oda a la muerte y la desolación. Es este primer título, consistente en el canto al régimen franquista, el que

\footnotetext{
${ }^{1}$ Diego San José (2018), Memorias de un gato. Valencina de la Concepción (Sevilla), Biblioteca de la Memoria, Renacimiento

${ }^{2}$ Diego San José (2016), De cárcel en cárcel. Valencina de la Concepción (Sevilla), Biblioteca de la Memoria, Renacimiento

${ }^{3}$ Juan Antonio Ríos Carratalá (2015), Nos vemos en Chicote. Imágenes del cinismo y el silencio en la cultura franquista, Valencina de la Concepción (Sevilla), Los cuatro vientos, Renacimiento
} 
fue utilizado por José García Fernández en su libro Al paso alegre de la paz, donde conformó una distópica situación tras la guerra.

Ante esta primera edición han surgido numerosos interrogantes que han quedado oscurecidos por innegables afirmaciones, muy del gusto de la época por enmudecer a los hijos de la patria. Son, en términos de fidelidad narrativa, aquellos problemas que se contemplan. Pero, dada la concreción histórica, no podemos los lectores dudar de la palabra de San José. Su vida y las circunstancias personales son contemporáneas a lo que se narra. No sería, por tanto, necesaria ninguna explicación si el testimonio de San José fuera fruto de la invención.

Quebrantando una libertad aparente, el madrileño comienza su novela de manera tan caótica como emocionante. El ajetreo y el tránsito de la población madrileña cambiarán en poco tiempo, y las calles y avenidas llenas de vida pronto quedarán vacías pero llenas de escombros. Un brusco cambio que va prediciendo la prensa y la radicalización de los actos.

Este guiño al periodismo deja ver la innegable familiarización de San José con este campo, de ahí que muchos de los diarios en los que colaborara estén reflejados o citados en sus páginas. Se trata de una relación que supone el punto de partida para introducir al protagonista y a su contrario. Rosario y Polito serán los dos intérpretes del choque y la contienda, enfrentados el uno al otro, pero unidos por un pasado que poco a poco se va quebrando. Esta dura cruzada, según apunta el escritor al referirse a la Guerra Civil, estará condicionada por el inevitable devenir de la guerra y el futuro de los propios personajes, siempre preocupados por la llegada de las tropas franquistas, que iban comiendo terreno y adentrándose en la villa de Madrid.

El destello de las bombas obliga a hacer una parada en la mayoría de los capítulos otorgando una base histórica sólida a la narración. La muerte de niños y mujeres, exterminando así la descendencia izquierdista y los propios asesinatos a personas de orden, hacen que el lector se estremezca desde su sitio, quede perplejo por la dureza de las descripciones y lo abominable que puede llegar a ser el ser humano cuando las creencias superan a la propia humanidad. En muchos de estos casos, la pausa o digresión que se produce en la acción principal hace que la narración quede detenida e inmóvil. No hay palabras para describir la impotencia que una persona siente ante la violación de su madre, ante el asesinato de sus padres o la mutilación de sus hijos.

Eco de los propios proyectiles, el lector se inmiscuye dentro de esas corralas de vecinos enclaustrados en los sótanos de los edificios. Sus largos diálogos, el miedo a la muerte y el estruendo de los explosivos son los únicos compañeros que esos vecinos pueden tener. Es tan particular esta situación que Fernando Fernán Gómez en Las bicicletas son para el verano se basa para construir su obra de teatro, centrada esta en aquellos momentos en que la vida madrileña se desarrolló en cárceles soterradas. 
Al desarrollo de la crónica de guerra acompaña la trama novelesca, aquella que nos induce a viajar a un tiempo pasado, y menos brillante. La fusión episódica, como tal, contiene un trasfondo antiguo que queda patente en la distribución que Diego San José dispone. Si hacemos memoria, podríamos ver la influencia del Lazarillo de Tormes, que es tan del gusto de este escritor. Esa fusión muestra un modus vivendi de los personajes, que siempre son vistos, sin embargo, desde la perspectiva del espectador.

A raíz de esta interacción formal con el Lazarillo y gracias al prólogo de Salazar Anglada, sabemos que la fuente de todos los males es la crónica más bien paródica, pero enmarcada por una realidad intransigente y cruda. Podríamos decir que la apariencia inicial dista mucho del título.

Evidenciando los datos e ideología que parecen entreverse entre las páginas y en el propio título, el planteamiento que presenta la formación novelesca radica en la propia situación sufrida y padecida por el madrileño. Es cierto que este estuvo recluido en varias cárceles y que su vida no se vio recompensada con la fama que adquirió durante los años de la República. La libertad que le granjeó la apertura de ideales fue uno de los puntos en que la literatura, a grandes rasgos, sufrió un crecimiento, y con ello, la mentalidad. En este caso, si seguimos la novela, son muchos los puntos que enfrentan la dualidad libertad-prohibición. Los tiempos de guerra, generalmente, conllevan una represión de libertad de expresión.

Otra de las cuestiones en la que incurre es en las descripciones de las cárceles ${ }^{4}$ madrileñas y las que fueron abriendo después de la victoria de Franco. Detalles que nos llevan a la desolación y pobreza absoluta ya que, cuando estos hechos tuvieron lugar, la moneda existente quedó obsoleta y toda la riqueza republicana no tenía cabida dentro del Régimen.

Esa riqueza se forjó en todos los ámbitos, incluido el literario. La representación de las adaptaciones de Fuenteovejuna de San José y La Numancia cervantina de Rafael Alberti y María Teresa León fueron algunas de las más llamativas propuestas en teatros en plena contienda. Es gracias a esto que Aníbal Salazar Anglada comenta que «Diego San José había ya adaptado algunos clásicos, como por ejemplo $L a$ gitanilla y La ilustre fregona, dos de las Novelas Ejemplares de Cervantes, que, convertidas en piezas teatrales, fueron estrenadas en el Teatro Español» (2020: 161162), lo que nos hace pensar que la cultura, a pesar de las circunstancias seguía en activo. Cabida, también, tienen grandes figuras de la época como Eduardo Zamacois o Joaquín Dicenta, dos grandes compañeros de profesión de San José.

\footnotetext{
${ }^{4}$ «A las siete y media, casi noche cerrada, comencé a oír un estrépito de cerrojos descorridos. Era que el cabo de la galería, iba abriendo celdas» (San José, 2016: 322)
} 
Dejando el panorama literario, no siendo ajeno el escritor a las cuestiones políticas y nacionales, perpetra una red de datos para el entendimiento de lo que se escondía tras muchos de los asesinatos y detenciones: la llamada «brigada del amanecer». Tal como está presentada, se trataba de un grupo especial de investigación con funciones plenamente confidenciales y policiales que actuaba en Madrid. Tal importancia contiene que el protagonista, Polito, forma parte de este y por ello asciende tras la victoria.

Es a raíz del alzamiento de poderes que la Iglesia, un reducto de crítica también incluido, pone su grano de arena para fomentar el odio contra los supuestos revolucionarios republicanos. La visión, plenamente paródica y crítica de San José, demuestra que hoy en día se asocia lo que es Iglesia con la derecha política y no con la izquierda, de ahí que cuando las tropas franquistas entraron en Madrid todo el clero, ya fueran monjas de clausura o curas de barrio, salieron a las calles a celebrar la victoria, una actuación evidente ya que fueron castigados duramente durante el periodo de libertad, aunque en este caso, tal actuación es mostrada como algo reprochable y vergonzoso: «quédese ello para cuando la Historia pueda escribirse de manera imparcial, con gran acopio de datos, como han escrito los de las guerras carlistas en las que nuestra Santa Madre Iglesia se portó como quien siempre tuvo costumbre: A Dios rogando y el hisopo dando» (2020: 278).

Finalmente, añadiendo una conclusión a lo indagado y reflejado en la novela editada, Diego San José, a modo de epílogo, añade un final inesperado a esta historia, subrayando ciertas consideraciones y juicios que dejan presente el patriotismo y la libertad, esa que faltó durante toda la guerra. Esa que quebró la vida, rompió familias y degradó a España con asesinatos, encarcelamientos y represión. Una censura que estuvo presente hasta la muerte del dictador. Con este acto simbólico de la publicación de Por Dios y por España se cierra, o eso esperemos, una etapa de nuestra historia en donde la libertad quedó relegada al pasado, donde la vida de nuestros amigos y familiares pendía de un hilo, donde no existía el bien ante la maldad. La guerra mata, pero la literatura siempre vive. Lo que nunca podrá cambiar es la libertad de ser quien somos. Y todos somos libres. 